\title{
Synthesis of skeletally diverse alkaloid-like molecules: exploitation of metathesis substrates assembled from triplets of building blocks
}

\author{
Sushil K. Maurya ${ }^{1,2}$, Mark Dow ${ }^{1,2}$, Stuart Warriner ${ }^{1,2}$ and Adam Nelson ${ }^{* 1,2}$
}

\section{Full Research Paper}

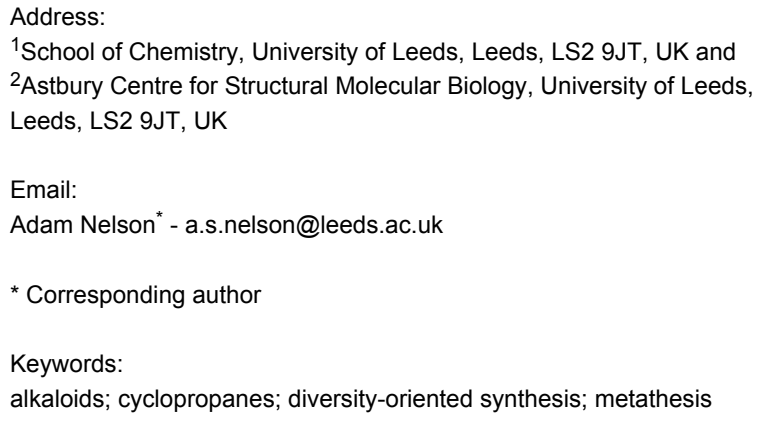

${ }^{1}$ School of Chemistry, University of Leeds, Leeds, LS2 9JT, UK and

${ }^{2}$ Astbury Centre for Structural Molecular Biology, University of Leeds, Leeds, LS2 9JT, UK

Email:

Adam Nelson* - a.s.nelson@leeds.ac.uk

* Corresponding author

Keywords:

alkaloids; cyclopropanes; diversity-oriented synthesis; metathesis

Open Access

\author{
Beilstein J. Org. Chem. 2013, 9, 775-785. \\ doi:10.3762/bjoc.9.88 \\ Received: 10 January 2013 \\ Accepted: 18 March 2013 \\ Published: 22 April 2013 \\ This article is part of the Thematic Series "Creating complexity". \\ Guest Editor: D. Craig \\ (c) 2013 Maurya et al; licensee Beilstein-Institut. \\ License and terms: see end of document.
}

\begin{abstract}
A range of metathesis substrates was assembled from triplets of unsaturated building blocks. The approach involved the iterative attachment of a propagating and a terminating building block to a fluorous-tagged initiating building block. Metathesis cascade chemistry was used to "reprogram" the molecular scaffolds. Remarkably, in one case, a cyclopropanation reaction competed with the expected metathesis cascade process. Finally, it was demonstrated that the metathesis products could be derivatised to yield the final products. At each stage, purification was facilitated by the presence of a fluorous-tagged protecting group.
\end{abstract}

\section{Introduction}

Our collective understanding of the biological relevance of chemical space has been shaped, in large part, by the historic exploration of chemical space by chemical synthesis (and biosynthesis) [1]. The scaffolds of known bioactive small molecules, in particular, play a key role in guiding the navigation of chemical space [2-4]. The field of biology-oriented synthesis (BIOS) [5], for example, uses biologically validated scaffolds [6-8] to inspire library design.

Known organic molecules populate chemical space unevenly and unsystematically. Around half of all known organic com- pounds are based on only $0.25 \%$ of the known molecular scaffolds [9]! This uneven coverage of chemical space is also typical of small-molecule screening collections $[7,10]$. Consequently, the biological relevance of most known scaffolds has been poorly explored. The field of diversity-oriented synthesis [11-13] has emerged with the specific aim of populating screening collections with diverse and novel small molecules.

We have previously developed a robust approach for the synthesis of skeletally diverse small molecules (Scheme 1) [14]. The approach relied on the synthesis of metathesis substrates by 


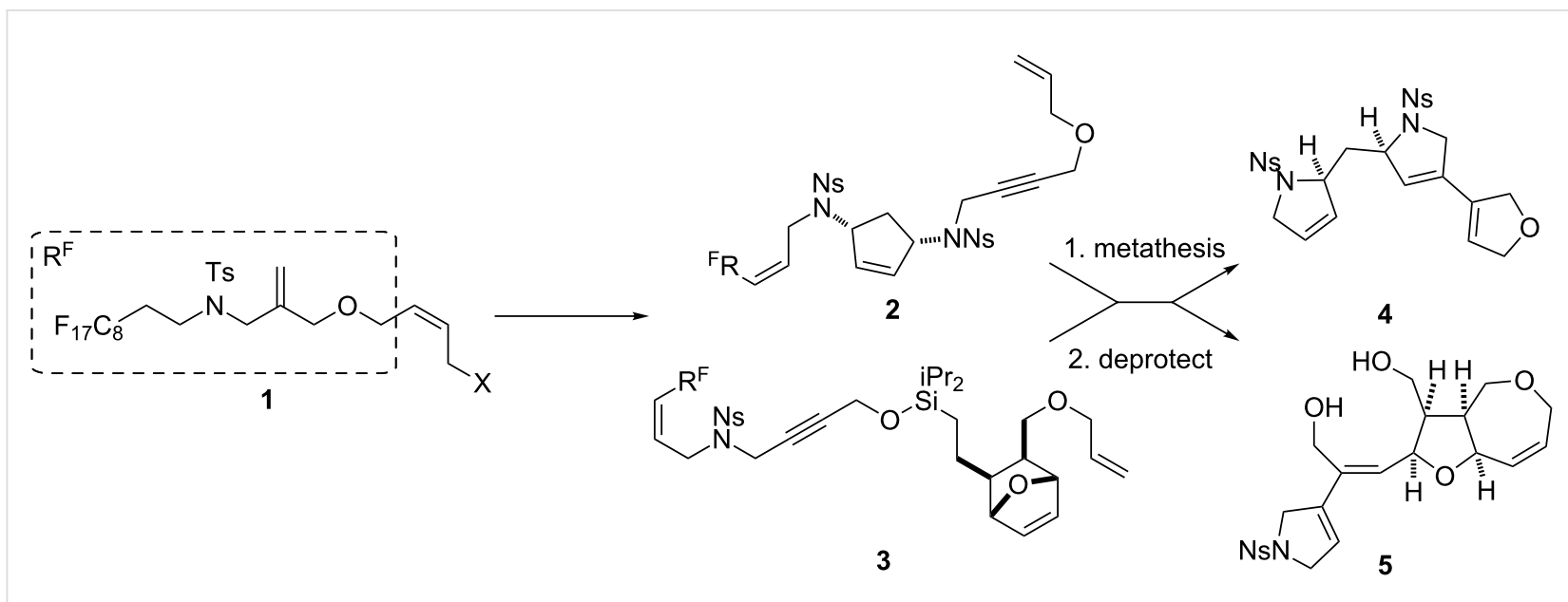

Scheme 1: Illustrative examples of a synthetic approach to natural-product-like molecules with over eighty molecular scaffolds.

iterative attachment of simple unsaturated building blocks to a fluorous-tagged linker $\mathbf{1}$ (e.g., $\rightarrow \mathbf{2}$ or $\mathbf{3}$ ). Subsequently, metathesis cascade reactions were used to "reprogram" the molecular scaffolds, concomitantly releasing the products from the linker (e.g., $\rightarrow \mathbf{4}$ or 5) [14-17]. The approach enabled the combinatorial variation of molecular scaffolds, and was exploited in the synthesis of natural-product-like small molecules with unprecedented scaffold diversity (over 80 distinct scaffolds).

Although powerful, this general approach to skeletally diverse molecules had only been exemplified by varying pairs of unsaturated building blocks [14]. Thus, by exploiting the linker 1, which is an allyl alcohol or allyl amine equivalent, all of the products were inevitably allylic alcohols or cyclic allylic amines. Here, we demonstrate that the approach is considerably more general, and that it is feasible to exploit triplets of building blocks, extending the range of diverse molecular scaffolds that may be prepared.

\section{Results and Discussion Library design}

An overview of the proposed approach to the synthesis of diverse scaffolds is shown in Scheme 2. The building blocks used in this study are shown in Figure 1. It was planned to start with an "initiating" building block (e.g., 6a or 7) bearing a fluorous tag to facilitate the purification of synthetic intermediates [18]. Iterative attachment of a propagating and a terminating building block would yield a metathesis substrate (such as 14 or 16). Finally, a metathesis cascade reaction would yield a product scaffold (such as $\mathbf{1 5}$ and 17). It was planned that many of the product scaffolds would bear an $o$-nitrophenylsulfonyl protecting group. The combinations of building blocks were carefully chosen to ensure that, after deprotection, selective derivatisation of the product scaffolds would be possible.

\section{Synthesis of building blocks}

The initiating building blocks $6 \mathbf{a}$ and $\mathbf{6 b}$ were prepared by using the approach outlined in Scheme 3. The allylic alcohol 14 [19]

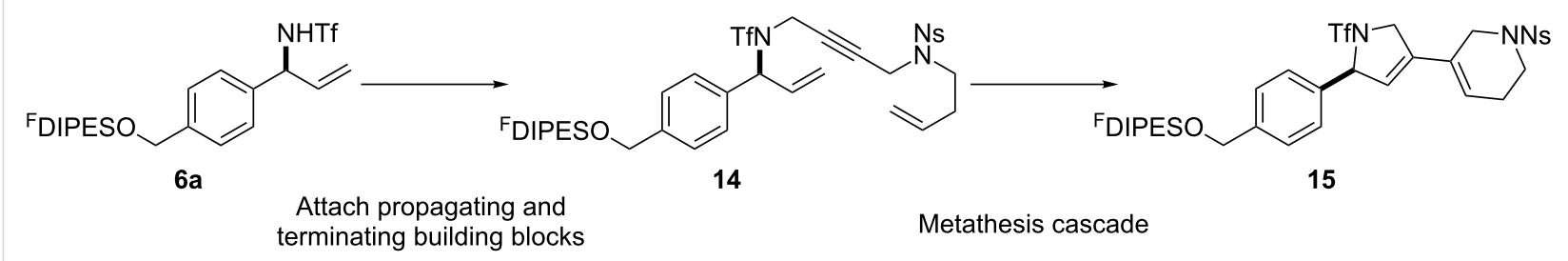

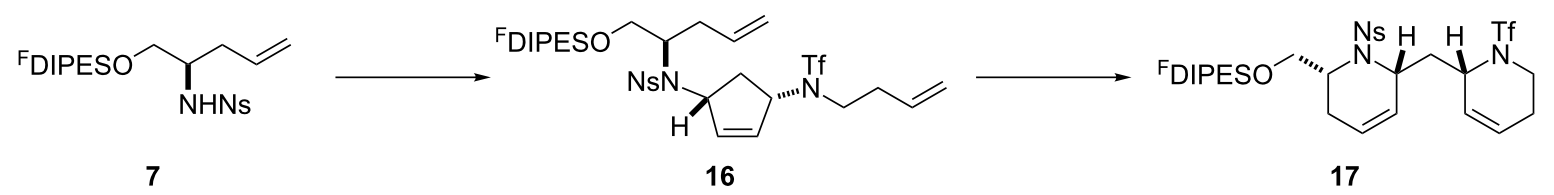

Scheme 2: Overview of the proposed synthetic approach. ${ }^{F}$ DIPES $=$ diisopropyl $(3,3,4,4,5,5,6,6,7,7,8,8,9,9,10,10,10$-heptadecafluorodecyl)silyl; $\mathrm{Ns}=$ o-nitrophenylsulfonyl. 


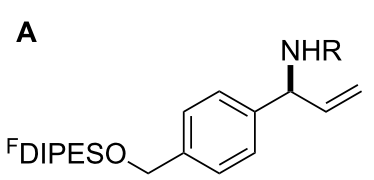

6a; $R=T f$

6b; $R=N s$

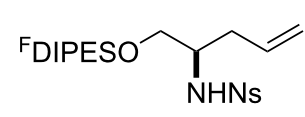

7
B<smiles>CC(C)OCC#CCO</smiles>

8

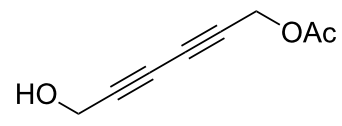

9<smiles>CC(=O)OC1C=CC(O)C1</smiles>

10<smiles>CC(=O)OC[C@@H]1C=C[C@H](CO)C1</smiles>

11
C

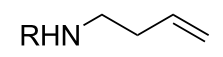

12a; $R=T f$

$12 b ; R=N s$

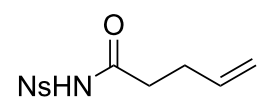

13

Figure 1: Structures of building blocks used in this study. Panel A: fluorous-tagged initiating building blocks. Panel B: propagating building blocks. Panel C: terminating building blocks.<smiles>C=CC(N)c1ccc(COS(=O)(=O)OCc2ccc(C(C=C)N=S)cc2)cc1</smiles>

Scheme 3: Synthesis of the initiating building blocks $6 \mathbf{a}$ and $\mathbf{6 b}$. TBD = 1,5,7-triazabicyclo[4.4.0]dec-5-ene.

was converted into the allylic carbonate 15 by treatment with methyl chloroformate and DMAP. The allylic carbonate $\mathbf{1 5}$ underwent efficient asymmetric allylic amination [20] with $o$-nitrophenylsulfonamide as the nucleophile to give the allylic sulfonamide 17 in $66 \%$ yield; in addition, the linear product 16 was also obtained in 7\% yield. Desilylation of $\mathbf{1 7}(\rightarrow \mathbf{1 8})$ and reaction with diisopropyl $(3,3,4,4,5,5,6,6,7,7,8,8,9,9,10,10,10$ heptadecafluorodecyl)silyl ( ${ }^{\mathrm{F} D I P E S}$ ) bromide, generated in situ from the corresponding silyl hydride, gave the fluorous-tagged building block 6b. Finally, desulfonylation $(\rightarrow 19)$ and trifluoromethylsulfonylation yielded the alternative initiating building block $\mathbf{6 a}$.

The initiating building block 7 was prepared from the sulfinimine 21 by adapting a synthesis previously reported by Ellman (Scheme 4) [21]. Treatment of the sulfinimine 21 in dichloromethane with allylmagnesium bromide yielded the corresponding sulfinimides as a 79:21 mixture of diastereoiomers; 


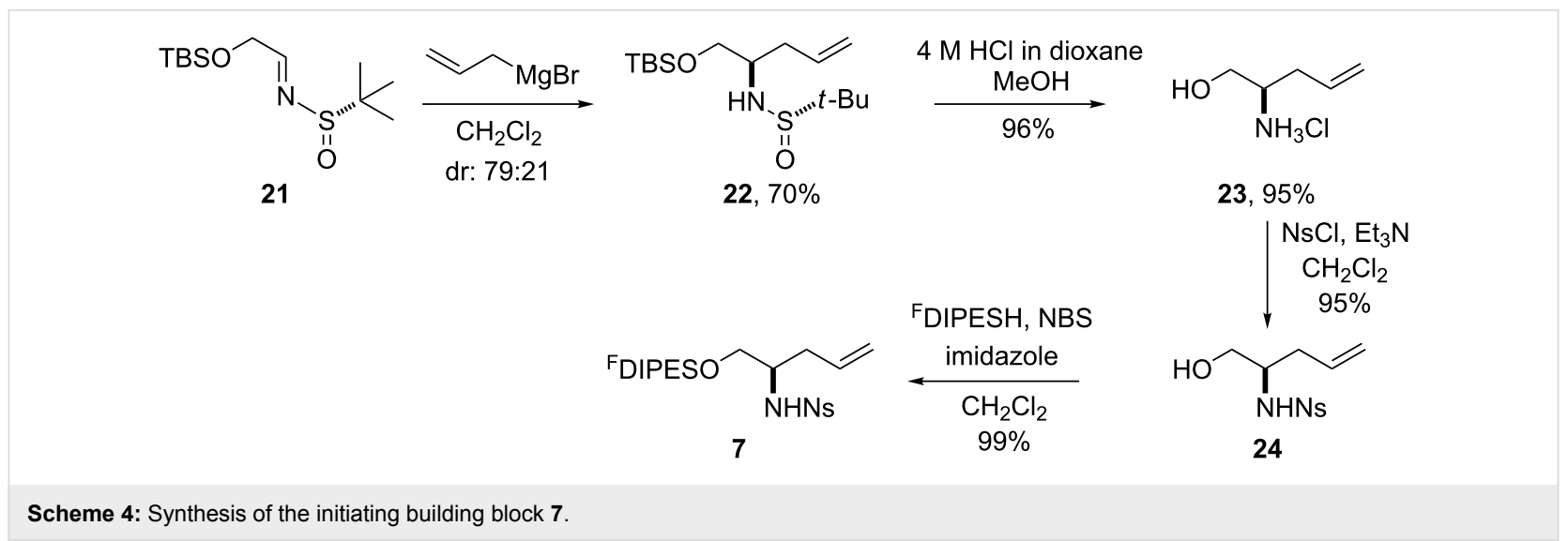

following column chromatography, the major diastereomer 22 was obtained in $70 \%$ yield, and was converted into the corresponding amino alcohol $\mathbf{2 3}$. The configuration of the amino alcohol 23 was determined by conversion into the corresponding benzamide and comparison with racemic and enantiomerically enriched samples (prepared from the commercially available amino acid). Analysis by chiral HPLC indicated that the amino alcohol $\mathbf{2 3}$ had $(R)$-configuration. It was concluded that the sense of diastereoselectivity in the addition $\mathbf{2 1} \rightarrow \mathbf{2 2}$ contrasted with that reported by Ellman [21]. However, the sense of diastereoselectivity was the same as that reported for the addition of allylmagnesium bromide in dichloromethane to a similar sulfinimine [22]. The amino alcohol $\mathbf{2 3}$ was converted into the corresponding $o$-nitrophenylsulfonamide $\mathbf{2 4}$ and, hence, the fluorous-tagged building block 7 .

The propagating building blocks $\mathbf{8}-\mathbf{1 1}$, and the terminating building block $\mathbf{1 2 b}$, were prepared by using established methods [14]. The enantiomeric excess ( $68 \%$ ee) of the hydroxy alcohol 11 was determined by conversion into the corres- ponding diastereomeric $O$-methyl mandelate esters. The terminating building blocks 12a and $\mathbf{1 3}$ were prepared by straightforward derivatisation of commercially available starting materials (see Supporting Information File 1).

\section{Synthesis of metathesis substrates}

Initially, the propagating building blocks $\mathbf{8}-\mathbf{1 1}$ were attached to the fluorous-tagged initiating building blocks (6a, $6 \mathbf{b}$ or 7$)$. In each case, an excess of the propagating building block, DEAD and triphenylphosphine was used. In general, the crude product was directly deacetylated. At each stage, the required fluoroustagged product was isolated by fluorous-solid-phase extraction (F-SPE), and its purity determined by analysis by $500 \mathrm{MHz}$ ${ }^{1} \mathrm{H}$ NMR spectroscopy. These results are summarised in Table 1.

The metathesis substrates were prepared by subsequent attachment of a terminating building block (12a, 12b or 13) (see Table 2). In each case, an excess of the terminating building block, DEAD and triphenylphosphine was used; the required

Table 1: Attachment of propagating building blocks to the fluorous-tagged initiating building blocks.

$\begin{array}{lll}\text { Building blocks } & \text { Attachment } & \begin{array}{l}\text { Method } \\ \left\{\mathrm{Purity}^{\mathrm{b}} / \%\right\}\end{array}\end{array}$


Table 1: Attachment of propagating building blocks to the fluorous-tagged initiating building blocks. (continued)

$6 a, 10$

A3 (85) $\{>98\}$

$6 b, 11^{d}$

A3 (85) $\{76\}$

A3 (92) $\{91\}$

A3 (74f)

7,10

A3 (97) $\{91\}$
87 (98)<smiles>C=C[C@H](NC1C=C[C@@H](O)C1)c1ccc(COS(F)(F)F)cc1</smiles>

$85^{\mathrm{e}}(72)$<smiles>C=CC([Sn]C[C@H]1C=C[C@H](CO)C1)c1ccc(CO[R5](F)F)cc1</smiles>

28

$94^{f}$

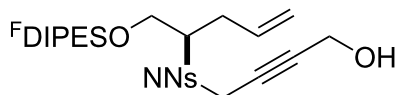

29<smiles>C=CCC(CO[SH](=O)(F)F)[N+](=O)[O-]</smiles>

30

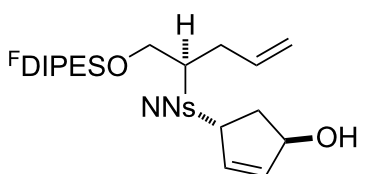

31

aMethods: A1: Initiating building block (1.0 equiv), propagating building block (4.0 equiv), DEAD (4.0 equiv), $\mathrm{PPh}_{3}\left(4.0\right.$ equiv), $\mathrm{CH}_{2} \mathrm{Cl}{ }_{2}, 0{ }^{\circ} \mathrm{C} \rightarrow \mathrm{rt}$ then F-SPE; A2: Initiating building block (1.0 equiv), propagating building block (4.0 equiv), DEAD (2.0 equiv), $\mathrm{PPh}_{3}(2.0 \mathrm{equiv}), \mathrm{CH}_{2} \mathrm{Cl}_{2}, 0{ }^{\circ} \mathrm{C} \rightarrow \mathrm{rt}$ then F-SPE; A3: Initiating building block (1.0 equiv), propagating building block (4.0 equiv), DEAD (2.0 equiv), $\mathrm{PPh}_{3}\left(2.0\right.$ equiv), $\mathrm{THF}, 0^{\circ} \mathrm{C} \rightarrow \mathrm{rt}$ then F-SPE; Deacetylation: $0.025 \mathrm{M} \mathrm{NH}_{3}$ in MeOH. ${ }^{\mathrm{b}}$ Determined by analysis of the $500 \mathrm{MHz}{ }^{1} \mathrm{H}$ NMR spectrum. ${ }^{\mathrm{C}}$ The building block had $>98 \%$ ee. ${ }^{\mathrm{d}}$ The

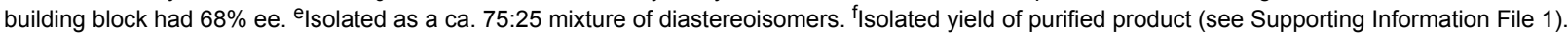

Table 2: Attachment of propagating building blocks to the fluorous-tagged initiating building blocks.

$\begin{array}{lll} & \text { Terminating } & \text { Attachment } \\ \text { building block } & \text { Product }\end{array}$

Method $^{a}$ (mass recovery / \%)

$\{$ Purity $\mathrm{b} \%$ \}

A4 (89) $\{86\}$

26
A4 (89) $\{83\}$<smiles>C=CCCN(CC)CC#CCNC(C=C)c1ccc(COS(=O)(=O)F)cc1</smiles>

32<smiles></smiles>

33<smiles>C=CCCN(C)CC#CC#CCNC(C=C)c1ccc(COS(=O)(F)=S)cc1</smiles> 
Table 2: Attachment of propagating building blocks to the fluorous-tagged initiating building blocks. (continued)

26

13

A4 (75) $\{97\}$

27

$12 b$

A5 $\left(62^{C}\right)$

27

13

A5 $\left(54^{\mathrm{C}}\right)$

$28^{d}$

$28^{d}$

29

$12 a$

13

$12 a$

A5 $\left(86^{\mathrm{c}, \mathrm{e}}\right)$

A5 $\left(77^{\mathrm{c}, \mathrm{e}}\right)$

A6 $\left(86^{\mathrm{C}}\right)$

29

13

30

$12 a$

13<smiles>C=CCCC(=O)N(CC#CC#CCNC(C=C)c1ccc(COS(=O)(F)=S)cc1)C(F)F</smiles>

35<smiles>C=CCCS[C@H]1C=C[C@@H](N[C@@H](C=C)c2ccc(CO[SH](=O)(F)F)cc2)C1</smiles>

36<smiles>C=CCCC(=O)S[C@H]1C=C[C@@H](N[C@@H](C=C)c2ccc(COS(=O)(=O)F)cc2)C1</smiles><smiles>C=CCCN([Tl])C[C@@H]1C=C[C@H](CSC(C=C)c2ccc(COS(F)(F)F)cc2)C1</smiles>

38<smiles>C=CCCC(=O)NC[C@@H]1C=C[C@H](CS[C@H](C=C)c2ccc(CO[R5](F)F)cc2)C1</smiles>

39

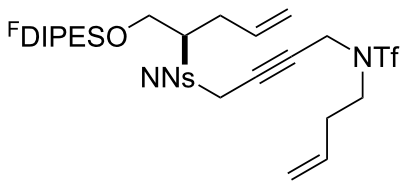

40<smiles>C=CCC(COS(=O)(=O)F)[Sn](N)CC#CCN(C)S(=O)(=O)F</smiles>

41

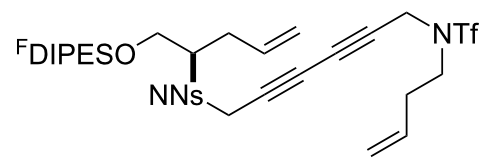

42

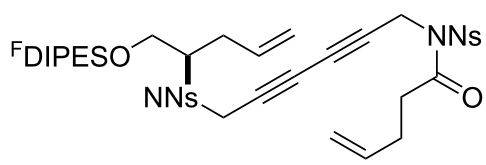

43 
Table 2: Attachment of propagating building blocks to the fluorous-tagged initiating building blocks. (continued)

31

$12 \mathrm{a}$

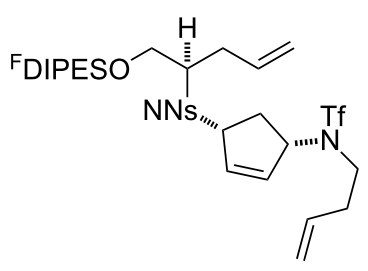

44

${ }^{a}$ Methods: A4: Substrate (1.0 equiv), propagating building block (4.0 equiv), DEAD (2.0 equiv), $\mathrm{PPh}_{3}$ (2.0 equiv), $\mathrm{CH}_{2} \mathrm{Cl}_{2}, 0^{\circ} \mathrm{C} \rightarrow \mathrm{rt}$ then $\mathrm{F}-\mathrm{SPE}$; A5: Substrate (1.0 equiv), propagating building block (4.0 equiv), DEAD (4.0 equiv), $\mathrm{PPh}_{3}$ (4.0 equiv), THF, $0^{\circ} \mathrm{C} \rightarrow \mathrm{rt}$ then F-SPE; A6: Substrate (1.0 equiv), propagating building block (4.0 equiv), DEAD (2.0 equiv), $\mathrm{PPh}_{3}\left(2.0\right.$ equiv), THF, $0{ }^{\circ} \mathrm{C} \rightarrow \mathrm{rt}$ then $\mathrm{F}-\mathrm{SPE}$. ${ }^{\mathrm{b}}$ Determined by analysis of the

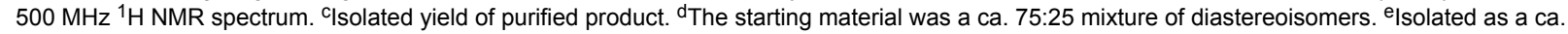
$75: 25$ mixture of diastereomers.

fluorous-tagged product was isolated by solid-fluorous phase extraction (F-SPE), and its purity was determined by analysis by $500 \mathrm{MHz}{ }^{1} \mathrm{H}$ NMR spectroscopy.

\section{Metathesis cascade reactions}

The scaffolds of the metathesis substrates were "reprogrammed" by treatment with Hoveyda-Grubbs second-generation catalyst in either dichloromethane or tert-butyl methyl ether [23] (TBME). Many of the metathesis reactions were rather sluggish, and the catalyst was added portionwise until the reac- tions were judged to be complete by TLC analysis. After removal [24] of the catalyst by using tris(hydroxymethyl)phosphine, the metathesis products were generally purified by flash column chromatography. Finally, the $o$-nitrophenylsulfonyl groups were removed from the products. The results are summarised in Table 3.

In general, the metathesis reactions proceeded smoothly to give the expected metathesis cascade products. In the case of $\mathbf{3 9}$, however, the cyclopentene did not participate in the metathesis

Table 3: Application of cascade metathesis reactions in the synthesis of diverse scaffolds and subsequent desulfonylation.

Substrate $\quad$ Methoda $^{\mathrm{a}}$ (mol \%; time)<smiles>F[R5](F)=COc1ccc([C@@H]2C=C(C3=CCNCC3)CN2)cc1</smiles><smiles>FC(F)OCc1ccc([C@@H]2NCC3(C4=CCNCC4)C[C@H]23)cc1</smiles>

46, $11 \% \mathrm{~b}$

46<smiles>FC(F)=[SH]OCc1ccc([C@@H]2NC[C@@]3(C4=CCNCC4)C[C@H]23)cc1</smiles>

47<smiles>O=C1CCC=C(C2=C[C@H](c3ccc(CO)cc3)[N]C2)CN1</smiles>

48<smiles>O=S(=O)([R5]F)OCc1ccc([C@@H]2C=C(C#CC3=CCCNC3)CN2)cc1</smiles> 
Table 3: Application of cascade metathesis reactions in the synthesis of diverse scaffolds and subsequent desulfonylation. (continued)

36

B1 $(4 \times 5 ; 20 \mathrm{~d})$ then $\mathrm{C} 1$

$38^{\mathrm{d}}$

B1 $(3 \times 5 ; 14 d)$ then $C 1$

39

B1 $(4 \times 5 ; 20 \mathrm{~d})$ then C2

B2 $(5 ; 24 \mathrm{~h})$ then $\mathrm{C} 1$

B2 $(5 ; 24 \mathrm{~h})$ then $\mathrm{C} 2$

B2 $(3 \times 5 ; 7 d)$ then $\mathrm{C} 1$

42

43

B2 $(2 \times 5 ; 3 d)$ then $C 2$

44

B2 $(5 ; 24 \mathrm{~h})$ then $\mathrm{C} 1$

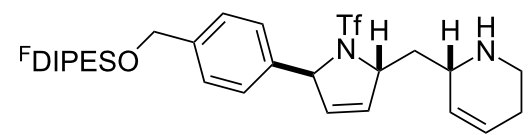

77 then $81\left(93 \%{ }^{c}\right)$

50

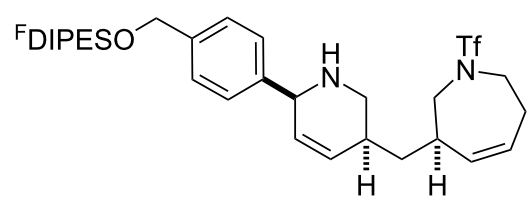

63 then $85(\mathbf{5 1})$

51<smiles>O=[SH](F)(OCc1ccc([C@@H]2C=C[C@H](CC3C=CCCN([Tl])C3)CN2)cc1)OC(F)F</smiles>

29 then $94(52)$

52<smiles>O=C(O)NC[C@H]1C=C[C@H](CN[C@@H](/C=C/CCC(=O)NC(F)(F)F)c2ccc(CO[SH](=O)(F)F)cc2)C1</smiles>

$8 \% \mathrm{~b}$

93 then $96\left(87 \%{ }^{c}\right)$

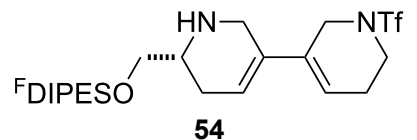<smiles>O=C1CCC=C(C2=CC[C@@H](COC=[Po])NC2)CN1</smiles>

55<smiles>O=C(OC[C@H]1CC=C(C#CC2=CCC[NH+]C2)CN1)[PH-]F</smiles>

76 then $92\left(92 \%{ }^{c}\right)$

56<smiles>O=C1CCC=C(C#CC2=CC[C@@H](CO[SH](F)F)NC2)CN1</smiles>

54 then $77\left(86 \%{ }^{c}\right)$

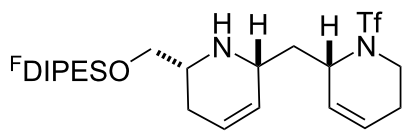

58

aMethods: B1: Hoveyda-Grubbs second-generation catalyst, $\mathrm{CH}_{2} \mathrm{Cl}_{2}, 50{ }^{\circ} \mathrm{C}$ then $\mathrm{Et}_{3} \mathrm{~N}$ (86 equiv), $\mathrm{P}\left(\mathrm{CH}_{2} \mathrm{OH}\right)_{3}$ (86 equiv) then silica; $\mathrm{B} 2$ : Hoveyda-Grubbs second-generation catalyst, MTBE, $50{ }^{\circ} \mathrm{C}$ then $\mathrm{Et}_{3} \mathrm{~N}$ (86 equiv), $\mathrm{P}\left(\mathrm{CH}_{2} \mathrm{OH}\right)_{3}\left(86\right.$ equiv) then silica; $\mathrm{C} 1: \mathrm{PhSH}\left(1.2\right.$ equiv), $\mathrm{K}_{2} \mathrm{CO}{ }_{3}$ (3.0 equiv), DMF; C2: $\mathrm{PhSH}$ (2.4 equiv), $\mathrm{K}_{2} \mathrm{CO}_{3}$ (6.0 equiv), DMF; $\mathrm{E}$ : aq $\mathrm{HF}, \mathrm{MeCN}-\mathrm{CH}_{2} \mathrm{Cl}_{2}$. bYield over more than one step. ${ }^{\mathrm{C}} \mathrm{Purity}$ of the product determined by $500 \mathrm{MHz}{ }^{1} \mathrm{H}$ NMR spectroscopy. ${ }^{\mathrm{d}}$ The starting material was a ca. 75:25 mixture of diastereoisomers.

reaction, and the bridged macrocycle $\mathbf{5 3}$ was obtained in low yield. We have previously observed the formation of macrocyclic metathesis products in similar metathesis cascade reactions [14]. The formation of the cyclopropanes 46 and 47 as byproducts in the metathesis cascade reaction of $\mathbf{3 2}$ was remarkable [25]. Presumably, in this case, the metathesis cascade leads to the generation of the intermediate 59 (Scheme 5); the intermediate could then react to conclude the 


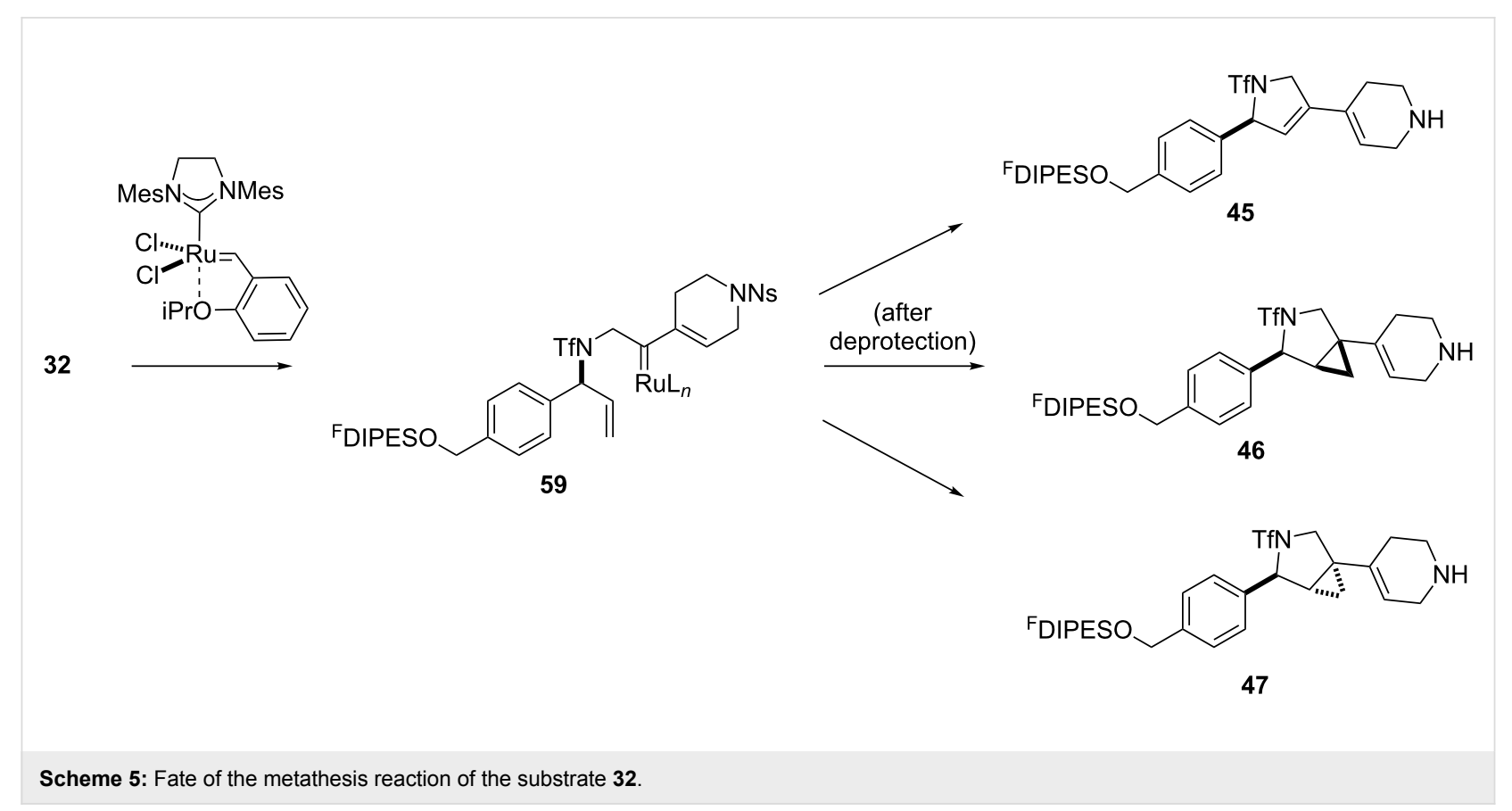

metathesis cascade (to give $\mathbf{4 5}$ after deprotection), or cyclopropanate [25] the terminal alkene (to give $\mathbf{4 6}$ or $\mathbf{4 7}$ after deprotection) (Scheme 5).
Finally, a selection of fluorous-tagged products was derivatised (typically on a $50 \mu \mathrm{mol}$ scale) to yield a range of amides and ureas (Table 4). The fluorous tag facilitated the purification of

\begin{tabular}{|c|c|c|c|c|}
\hline Substrate (puritya / \%) & Product $^{b}$ & \multirow{3}{*}{$\begin{array}{l}60 a \\
60 b\end{array}$} & \multirow{2}{*}{$\begin{array}{l}\text { Method } \\
\text { D }\end{array}$} & \multirow{2}{*}{$\begin{array}{l}\text { Yield / \% } \\
51\end{array}$} \\
\hline \multirow{4}{*}{45} & \multirow{4}{*}{$\mathrm{HO} \sim$} & & & \\
\hline & & & E1 then D & 81 then 60 \\
\hline & & $60 c$ & E2 then D & 67 then 98 \\
\hline & & $60 d$ & E3 then D & 94 then 81 \\
\hline 46 & & 61b & E1 then D & 39 then 70 \\
\hline 47 & & $62 b$ & E1 then D & 43 then 63 \\
\hline \multirow{4}{*}{$\begin{array}{l}49 \\
(86)\end{array}$} & & $63 a$ & $\mathrm{D}$ & 83 \\
\hline & & $63 b$ & E1 then D & 32 then 64 \\
\hline & & $63 c$ & E2 then D & 83 then 58 \\
\hline & & $63 d$ & E3 then D & 84 then 79 \\
\hline \multirow{4}{*}{$\begin{array}{l}\mathbf{5 0} \\
(93)\end{array}$} & & $64 a$ & $\mathrm{D}$ & 87 \\
\hline & & $64 b$ & E1 then D & $29^{d}$ \\
\hline & & $64 c$ & E2 then D & $43^{d}$ \\
\hline & & $64 d$ & E3 then D & $34^{d}$ \\
\hline
\end{tabular}


Table 4: Derivatisation and deprotection of final products. (continued)

51 (85)

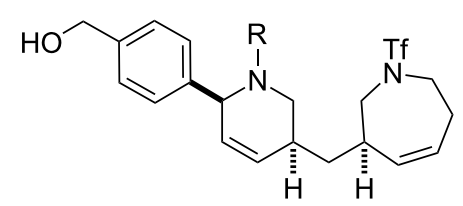

D

E1 then D

E2 then $D$

E3 then D
70

$40^{\mathrm{d}}$

$82^{d}$

$74^{\mathrm{d}}$

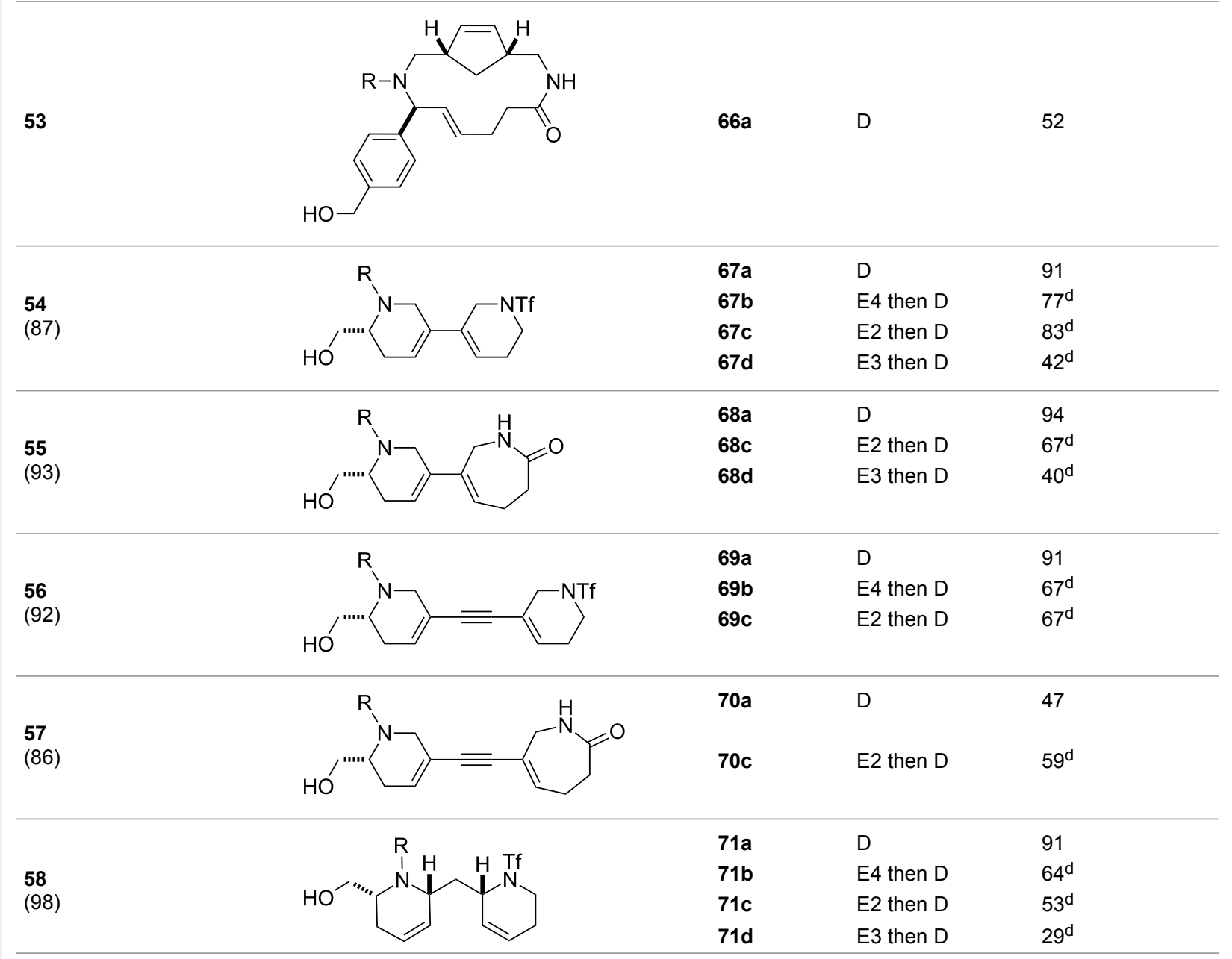

aDetermined by analysis of the product by $500 \mathrm{MHz}{ }^{1} \mathrm{H}$ NMR spectroscopy. ${ }^{\mathrm{b}}$ The suffix refers to the identity of the $\mathrm{R}$ substituent: $\mathrm{a}, \mathrm{R}=\mathrm{H}$; $\mathrm{b}, \mathrm{R}=$ isoxazole-5-carbonyl; c, $\mathrm{R}=$ pyridine-3-carbonylamino; $\mathrm{d}, \mathrm{R}=$ morpholine-4-carbonyl; 'Methods: $\mathrm{D}$ : aq $\mathrm{HF}, \mathrm{MeCN}^{\mathrm{C}} \mathrm{CH}_{2} \mathrm{Cl}_{2}$; $\mathrm{E} 1$ : isoxazole-5-carbonyl chloride (2.0 equiv), $\mathrm{Et}_{3} \mathrm{~N}$ (3.0 equiv), DMAP (1.0 equiv), $\mathrm{CH}_{2} \mathrm{Cl}_{2}$; $\mathrm{E2}$ : pyridine-3-isocyanate (2.0 equiv), $\mathrm{Et}_{3} \mathrm{~N}$ (3.0 equiv), DMAP (1.0 equiv), $\mathrm{CH}_{2} \mathrm{Cl}_{2}$; E3: morpholine-4-carbonyl chloride (2.0 equiv), $\mathrm{Et}_{3} \mathrm{~N}$ (3.0 equiv), DMAP (1.0 equiv), $\mathrm{CH}_{2} \mathrm{Cl}_{2}$; $\mathrm{E} 4$ : isoxazole-5-carbonyl chloride (2.0 equiv), pyridine; dYield over two steps.

the derivitised products by F-SPE. The final products 60-71 (Table 4) were obtained after removal of the fluorous tag by desilylation.

\section{Conclusion}

Metathesis is an extremely powerful reaction for diversityoriented synthesis. It was demonstrated that metathesis substrates could be assembled efficiently from triplets of building blocks. Thereafter, metathesis cascades yielded a diverse range of molecular scaffolds. The diversity of the products was increased through variation of all three of the building blocks used: the initiating, the propagating, and the terminating building block.

The overall approach was facilitated by fluorous tagging of the initiating building block, allowing easy purification (by F-SPE) of synthetic intermediates and metathesis products. The presence of a fluorous tag also facilitated the purification of the 
functionalised products. Evaluation of the biological activity of the final products will be reported in due course.

\section{Supporting Information}

\section{Supporting Information File 1}

Experimental and compound characterisation. [http://www.beilstein-journals.org/bjoc/content/ supplementary/1860-5397-9-88-S1.pdf]

\section{Acknowledgements}

We thank the European Commission for a Marie Curie International Incoming Fellowship (to S.K.M.) and the EPSRC for additional funding.

\section{References}

1. Paolini, G. V.; Shapland, R. H. B.; van Hoorn, W. P.; Mason, J. S.; Hopkins, A. L. Nat. Biotechnol. 2006, 24, 805-815. doi:10.1038/nbt1228

2. Wetzel, S.; Klein, K.; Renner, S.; Rauh, D.; Oprea, T. I.; Mutzel, P.; Waldmann, H. Nat. Chem. Biol. 2009, 5, 581-583. doi:10.1038/nchembio.187

3. Renner, S.; van Otterlo, W. A. L.; Dominguez Seoane, M.; Möcklinghoff, S.; Hofmann, B.; Wetzel, S.; Schuffenhauer, A.; Ertl, P.; Oprea, T. I.; Steinhilber, D.; Brunsveld, L.; Rauh, D.; Waldmann, H. Nat. Chem. Biol. 2009, 5, 585-592. doi:10.1038/nchembio.188

4. Hu, Y.; Wassermann, A. M.; Lounkine, E.; Bajorath, J. J. Med. Chem. 2010, 53, 752-758. doi:10.1021/jm9014229

5. Wetzel, S.; Bon, R. S.; Kumar, K.; Waldmann, H. Angew. Chem., Int. Ed. 2011, 50, 10800-10826. doi:10.1002/anie.201007004

6. Evans, B. E.; Rittle, K. E.; Bock, M. G.; DiPardo, R. M.; Freidinger, R. M.; Whitter, W. L.; Lundell, G. F.; Veber, D. F.; Anderson, P. S.; Chang, R. S. L.; Lotti, V. J.; Cerino, D. J.; Chen, T. B.; Kling, P. J.; Kunkel, K. A.; Springer, J. P. J. Med. Chem. 1988, 31 , 2235-2246. doi:10.1021/jm00120a002

7. Shelat, A. A.; Guy, R. K. Nat. Chem. Biol. 2007, 3, 442-446. doi:10.1038/nchembio0807-442

8. Hu, Y.; Stumpfe, D.; Bajorath, J. J. Chem. Inf. Model. 2011, 51, 1742-1753. doi:10.1021/ci200179y

9. Lipkus, A. H.; Yuan, Q.; Lucas, K. A.; Funk, S. A.; Bartelt, W. F., III; Schenck, R. J.; Trippe, A. J. J. Org. Chem. 2008, 73, 4443-4451. doi:10.1021/j08001276

10. Krier, M.; Bret, G.; Rognan, D. J. Chem. Inf. Model. 2006, 46, 512-524. doi:10.1021/ci050352v

11. O' Connor, C. J.; Beckmann, H. S. G.; Spring, D. R. Chem. Soc. Rev. 2012, 41, 4444-4456. doi:10.1039/c2cs35023h See for a recent review of diversity-oriented synthesis.

12. MacLellan, P.; Nelson, A. Chem. Commun. 2013, 49, 2383-2393. doi:10.1039/c2cc38184b

See for a recent review of diversity-oriented synthesis.

13. Nielsen, T. E.; Schreiber, S. L. Angew. Chem., Int. Ed. 2008, 47, 48-56. doi:10.1002/anie.200703073

See for a recent review of diversity-oriented synthesis.
14. Morton, D.; Leach, S.; Cordier, C.; Warriner, S.; Nelson, A. Angew. Chem., Int. Ed. 2009, 48, 104-109. doi:10.1002/anie.200804486

15. Spandl, R. J.; Rudyk, H.; Spring, D. R. Chem. Commun. 2008, 3001-3003. doi:10.1039/b807278g

See for other diversity-oriented approaches that exploit metathesis chemistry.

16. Spiegel, D. A.; Schroeder, F. C.; Duvall, J. R.; Schreiber, S. L. J. Am. Chem. Soc. 2006, 128, 14766-14767. doi:10.1021/ja065724a See for other diversity-oriented approaches that exploit metathesis chemistry.

17. O'Leary-Steele, C.; Pedersen, P. J.; James, T.; Lanyon-Hogg, T.; Leach, S.; Hayes, J.; Nelson, A. Chem.-Eur. J. 2010, 16, 9563-9571. doi:10.1002/chem.201000707

See for other diversity-oriented approaches that exploit metathesis chemistry.

18. Gladysz, A.; Curran, D. P.; Horváth, I. T. Handbook of Fluorous Chemistry; Wiley: New York, 2004. doi:10.1002/3527603905

19. Wuts, P. G. M.; Ashford, S. W.; Anderson, A. M.; Atkins, J. R. Org. Lett. 2003, 5, 1483-1485. doi:10.1021/ol034274d

20. Weinhofen, R.; Tverskoy, O.; Helmchen, G. Angew. Chem., Int. Ed. 2006, 45, 5546-5549. doi:10.1002/anie.200601472

21. Rech, J. C.; Yato, M.; Duckett, D.; Ember, B.; LoGrosso, P. V.; Bergman, R. G.; Ellman, J. A. J. Am. Chem. Soc. 2007, 129, 490-491. doi:10.1021/ja0676004

22. Koriyama, Y.; Nozawa, A.; Hayakawa, R.; Shimizu, M. Tetrahedron 2002, 58, 9621-9628. doi:10.1016/S0040-4020(02)01250-4

23. Kuhn, K. M.; Champagne, T. M.; Hong, S. H.; Wei, W.-H.; Nickel, A.; Lee, C. W.; Virgil, S. C.; Grubbs, R. H.; Pederson, R. L. Org. Lett. 2010, 12, 984-987. doi:10.1021/ol9029808

24. Maynard, H. D.; Grubbs, R. H. Tetrahedron Lett. 1999, 40, 4137-4140. doi:10.1016/S0040-4039(99)00726-1

25. Peppers, B. P.; Diver, S. T. J. Am. Chem. Soc. 2004, 126, 9524-9525. doi:10.1021/ja049079o

See for a reaction with a similar outcome.

\section{License and Terms}

This is an Open Access article under the terms of the Creative Commons Attribution License (http://creativecommons.org/licenses/by/2.0), which permits unrestricted use, distribution, and reproduction in any medium, provided the original work is properly cited.

The license is subject to the Beilstein Journal of Organic Chemistry terms and conditions:

(http://www.beilstein-journals.org/bjoc)

The definitive version of this article is the electronic one which can be found at: doi:10.3762/bjoc. 9.88 